\title{
The Research on Efficiency Evaluation and Optimization of Eco-tourism in Coastal Zone Based on Data Envelopment Analysis
}

\author{
PAN Wei, a ${ }^{1,}$ ZHAO Liyang ${ }^{2}$, ZHANG Xiaoxiao ${ }^{3}$, XUE Bo $^{4}$, DAI Shumeng ${ }^{5}$, \\ WANG Yu ${ }^{6}$, LI Dan ${ }^{7}$ \\ 1,2,3,4,5,6,7 Faculty of science,Mudanjiang Normal university, Mudanjiang 157012,China \\ apanwei916@yeah.net
}

Keywords: Seashore tourism; Eco-tourism; Data envelopment analysis; Efficiency evaluation

\begin{abstract}
This paper is based on ecology, environmental ecology, ecological carrying capacity and sustainable development, Marine science, economics, regional tourism development, DEA and other disciplines theory, according to the requirements of the condition of ecological tourist area determine, designs the evaluation project type coastal ecological tourist area and the evaluation scoring method of China's main coastal city ecological tourism environment quality evaluation, the DEA method is used for Chinese coastal city ecotourism development efficiency evaluation, and analyzes the evaluation results, put forward the optimized path.
\end{abstract}

\section{Introduction}

With the rapid development of tourism industry, coastal tourism as a Marine tourism core, ushered in the unprecedented development opportunity. However, should also see, seaside tourism in coastal tourism, water sports and leisure and other projects and the ecological environment and ecological tourism resources development and utilization of effect are closely related [1]. In the study found that, at present China's coastal city of ecological tourism environment quality overall level is not high, and the gap between the cities, the people in the tourism development at the same time, seem to ignore the ecological tourism, as the development of tourism in the 21st century persistent target this consensus on human subjects, and in the field of ecological tourism research, seashore ecotourism research relative lag, less coastal ecological evaluation of the efficiency of tourism, the DFA method is used to carry out the evaluation of basic is blank [2].

Therefore, this article is based on the DEA method was carried out by evaluation for the efficiency of China's coastal ecological tourism. In order to achieve the authenticity and validity of the evaluation results, this paper firstly made level for China's coastal city ecological environment evaluation, to select the evaluation indexes meet the requirements of the ecological tourism. This is also in this paper, different from the general urban tourism efficiency evaluation results of the key. Purpose is to hope to enrich and perfect China's coastal regional ecotourism and sustainable development theory, for the Chinese coastal city in the ecotourism development accurately determining the efficiency of input and output, determine the development steps and methods, reasonably provide methods and research data, the allocation of resources, as well as to guide eco-tourism, sustained and healthy development of China's coastal area.

\section{Overview of DEA model}

Data envelopment analysis (DEA) is a kind of new method of system analysis developed by Charmes A. and Cooper W. based on the concept of "relative efficiency evaluation". DEA is to evaluate is the use of mathematical programming model with multiple input and, especially, the decision making unit (DMU) relative effectiveness [3]. DEA is a kind of "data" oriented evaluation method, is used to evaluate a set of decision making units with multiple input and multiple output performance and relative efficiency. Due to the DEA method to individual differences, especially the efficiency of DMU has a unique advantage, but also can avoid a variety of restrictions of 
parameter method, so it is widely used in various fields, has become a management science and system engineering, a kind of important and effective analysis tool [4].

CCR model. Assume that a group surveyed the number of units for $n$, be reviewed each unit has $s$ output variable and $m$ input variable. $Y_{j k}$ said the first $k$ by investigation unit of the first $j$ output variable, $\mathrm{X}_{\mathrm{ik}}$ is the first the first $i$ input variable $k$ units. The first $k$ decision-making unit total efficiency calculation problem can be converted into linear programming problem as follows:

$\min \theta$

$$
\text { (C C R s.t. } \mid \begin{aligned}
& \sum_{j=1}^{n} X_{j} \lambda_{j} \leqslant \theta X_{k} \\
& \sum_{j=1}^{n} Y_{j} \lambda_{j} \geqslant Y_{k} \\
& \lambda \geqslant 0 . j=1 \ldots . . n
\end{aligned}
$$

In the formula (1), $\mathrm{X}_{\mathrm{k}}=\left(\mathrm{x}_{1 \mathrm{k}}, \mathrm{x}_{2 \mathrm{k}}, \ldots \mathrm{x}_{\mathrm{mk}}\right), \mathrm{Y}_{\mathrm{k}}=\left(\mathrm{y}_{1 \mathrm{k}}, \mathrm{y}_{2 \mathrm{k}}, \ldots \mathrm{y}_{\mathrm{sk}}\right)$. This model is known as the CCR model, is under assumption of constant return to scale.

Super efficiency DEA model. DEA CCR model of the decision-making unit is divided into two kinds of valid and invalid, and for effective decision making units at the same time, is unable to make the evaluation and comparison. In 1993, Andersen put forward a kind of super efficiency evaluation model of DEA efficient units. Super efficiency evaluation model similar to the CCR model mathematical form, the form is as follows:

$$
\text { s.t }\left\{\begin{array}{l}
\sum_{j=1 j \neq k}^{n} X_{j} \lambda_{j} \leqslant \theta X_{k} \\
\sum_{j=1}^{n} Y_{j} \lambda_{j} \geqslant Y_{k} \\
\lambda \geqslant 0 . j=1 \ldots . . n
\end{array}\right.
$$

BCC model. Linear programming (1) assuming constant return to scale, makes the operation on the efficient frontier face of increasing or decreasing return to scale of DMU is not DEA efficient evaluation results, but there was no distinguish is not effective in scale or technology.

$$
\operatorname{s.t}\left\{\begin{array}{l}
\sum \lambda_{\mathrm{J}} \mathrm{Y}_{\mathrm{J}} \geqslant \mathrm{Y}_{0} \\
\sum \lambda_{\mathrm{j}} \mathrm{X}_{\mathrm{J}} \leqslant \sigma \mathrm{X}_{0} \\
\sum \lambda_{\mathrm{J}}=1 \\
\lambda_{\mathrm{J}} \geqslant 0 \\
\mathrm{j}=1,2, \ldots, \mathrm{n}
\end{array}\right.
$$

BCC model introduced constraint $\sum \lambda_{I}=1$, remove the constant return to scale hypothesis, a pure technical efficiency can be unit. BCC model of the system is decomposed into pure technical efficiency and scale efficiency, namely the system efficiency = pure technical efficiency scale efficiency. It can around the pure technical efficiency refers to the effective use of production technology, to maximize output; It said inputs on the use of efficiency. Scale efficiency refers to whether the proportion of output and input properly, every year around the maximize output.

\section{Design of Eco-tourism plan efficiency}

DEA method in the calculation to evaluate efficiency of China's coastal region ecological tourism is the first step of work for the research object (decision making units) reasonable choice, in the hope of the late research results have representative and strong persuasion. Selection of object of study must be high quality of seaside tourism area, and the regional tourism resources should be strong appeal, have larger market share. In addition, the study area must be have a higher value of ecological tourism area, ecological tourist area ecological environment background conditions of the most basic requirements [5]. 
The determination of the object of study. In order to improve the efficiency of study, this article in the coastal regional and above merit was conducted again in the excellent tourist city, select the "main coastal excellent tourist city" to represent their highest level in the seashore area tourism development. Basic by two indexes which can reflect the regional tourism development level, market scale, the level of resources and tourist attraction, has the strong comparability and persuasive. This article finally confirmed Dalian, Qinhuangdao, Weihai, Yantai, Qingdao, Shanghai, Ningbo, Wenzhou, Xiamen, Guangzhou, Shenzhen, Sanya 12 cities as the research object of this article, the 12 cities in China's coastal, according with the actual status of the seaside tourism development in China. Represented by their research results basically can travel on behalf of the Chinese coastal ecological efficiency levels.

The determination of the index. Correct use of DEA method to evaluate the efficiency of China's coastal region ecological tourism is a basic premise is reasonable evaluation index, evaluation index to determine the need to follow the systematic, scientific, comparable and measurable principle to select input (input) and output (output).If there will be China's coastal region ecological tourism development as a process, so the above 12 coastal excellent ecological tourism city is ecological tourism decision making units of production.

Tourism study on regional tourism generally refers to the economic benefits, social benefits and environmental benefits of integrated production, so the above coastal city ecotourism directly output should contain the full value of the three major benefits. This article choose tourism revenue, total travel number and other two indicators as output index.

\section{The ecological tourism efficiency evaluation based on DEA}

According to the analysis of the above input and output, this article has carried on the data collection and calculation. Input index of the length of the coastline, employment in the tertiary industry, urban fixed asset investment and so on are shown in table 1.Tourism resources attraction index is according to the national tourism administration approval of a-class tourist scenic spots to quantify. Based on the above 3 a grade and high level scenic spots to calculate the composite attraction of tourism resources. Ecological environment attraction index is directly used in China's major coastal city ecological environment resources survey evaluation score. Output indicators of tourism revenue, travel number from the total number of Chinese regional economic statistical yearbook data calculated, are shown in table 2.

Table 1. Inputs index in the evaluation

\begin{tabular}{|c|c|c|c|c|c|c|c|c|c|}
\hline \multirow[b]{2}{*}{ Number } & \multirow[b]{2}{*}{ City } & \multicolumn{3}{|r|}{$\mathrm{B}$} & \multicolumn{2}{|c|}{$\mathrm{C}$} & $\mathrm{D}$ & \multicolumn{2}{|l|}{ E } \\
\hline & & Coastline & \multicolumn{2}{|c|}{$\begin{array}{l}\text { Second industry } \\
\text { workers }\end{array}$} & \multicolumn{2}{|c|}{$\begin{array}{l}\text { City fixed assets } \\
\text { investment }\end{array}$} & $\begin{array}{l}\text { Attractive tourism } \\
\text { resources }\end{array}$ & \multicolumn{2}{|c|}{$\begin{array}{c}\begin{array}{c}\text { Ecological environment } \\
\text { resources attraction }\end{array} \\
\end{array}$} \\
\hline 1 & Dalian & 1906 & \multicolumn{2}{|c|}{193.9} & \multicolumn{2}{|c|}{3113.7} & 59 & \multicolumn{2}{|c|}{153} \\
\hline 2 & Qinghuangdao & 162.7 & \multicolumn{2}{|r|}{52.9} & \multicolumn{2}{|c|}{257.27} & 40 & \multicolumn{2}{|l|}{160} \\
\hline 3 & Weihai & 986 & \multicolumn{2}{|r|}{52.3} & \multicolumn{2}{|c|}{1165.54} & 24 & \multicolumn{2}{|l|}{171} \\
\hline 4 & Yantai & 909 & \multicolumn{2}{|c|}{120.4} & \multicolumn{2}{|c|}{2222.17} & 60 & \multicolumn{2}{|l|}{155} \\
\hline 5 & Qingdao & 731 & \multicolumn{2}{|r|}{178.7} & \multicolumn{2}{|c|}{2458.89} & 57 & \multicolumn{2}{|l|}{163} \\
\hline 6 & Shanghai & 450 & \multirow{2}{*}{\multicolumn{2}{|c|}{$\begin{array}{l}534.2 \\
135.4\end{array}$}} & \multicolumn{2}{|c|}{7997.62} & 98 & \multicolumn{2}{|l|}{154} \\
\hline 7 & Ningbo & 1594 & & & \multicolumn{2}{|c|}{2048.19} & 56 & \multicolumn{2}{|l|}{158} \\
\hline 8 & Wenzhou & 339 & \multicolumn{2}{|c|}{$\begin{array}{l}135.4 \\
198.4\end{array}$} & & 4.93 & 43 & 155 & \\
\hline 9 & Xiamen & 234 & \multicolumn{2}{|r|}{113.4} & & 2.12 & 25 & 168 & \\
\hline 10 & Guangzhou & 550 & & 361.6 & & 59.85 & 62 & 152 & \\
\hline 11 & Shenzhen & 230 & & 318.4 & & 09.15 & 22 & 155 & \\
\hline 12 & Sanya & 259 & & 14.3 & & 1.39 & 30 & 186 & \\
\hline & $\mathrm{Ta}$ & le 2 & 2 & puts & & $\therefore$ & evalua & on & \\
\hline & & & & ourism reve & & & Total nu & umber of tourisn & \\
\hline Number & City & $\begin{array}{r}\text { Domes } \\
\text { tourism in }\end{array}$ & $\begin{array}{l}\text { tic } \\
\text { come }\end{array}$ & $\begin{array}{r}\text { Interna } \\
\text { tourism i }\end{array}$ & ional & Total & $\begin{array}{c}\text { Number of } \\
\text { domestic tourism }\end{array}$ & $\begin{array}{c}\text { International } \\
\text { tourist arrivals }\end{array}$ & Total \\
\hline 1 & Dalian & 430.5 & & 46. & & 477.0 & 3412.0 & 94.8 & 3506.8 \\
\hline 2 & Qinghuangdao & 122. & & 1.6 & & 129.6 & 1638.4 & 22.4 & 1660.8 \\
\hline 3 & Weihai & 177. & & 10. & & 187.9 & 1838.6 & 32.3 & 1870.9 \\
\hline 4 & Yantai & 2511. & & 19. & & 272.0 & 27617.0 & 40.1 & 2802.8 \\
\hline 5 & Qingdao & 451.4 & & 35. & & 486.7 & 39014.0 & 100.1 & 41303.5 \\
\hline 6 & Shanghai & 1913. & & 306 & & 2220.2 & 12361.0 & 533.4 & 12894.4 \\
\hline 7 & Ningbo & 497.3 & & 31. & & 528.4 & 3962.0 & 80.1 & 4042.1 \\
\hline 8 & Wenzhou & 2517. & & 11. & & 265.1 & 293.2 & 33.0 & 296167.0 \\
\hline 9 & Xiamen & 241.1 & & 57. & & 298.7 & 1788.2 & 128.2 & 1916.4 \\
\hline 10 & Guangzhou & 746.5 & & 231 & & 978.0 & 3286.1 & 68140.0 & 3975.5 \\
\hline 11 & Shenzhen & 355.7 & & 176 & & 532.3 & 1943.9 & 896.4 & 2840.3 \\
\hline 12 & Sanya & 90.5 & & 12. & & 103.0 & 637.3 & 31.8 & 66108.0 \\
\hline
\end{tabular}


The above-mentioned data distribution to appropriate DEA model to solve. According to the output of the results found that in Shanghai, Qinhuangdao, Sanya, Guangzhou, Wenzhou, Weihai, Shenzhen, Ningbo and Xiamen DEA efficient and DEA invalid such as Dalian, Yantai and Qingdao. To obtain discharge priorities, DEA efficient urban scale analysis, observe its ability of sustainable development. Analysis on DEA invalid cities also need to continue to find out the main reason for the invalid, optimization scheme is put forward.

\section{Conclusion}

Eco-tourism as tourism development in the 21st century after persistent goal this consensus on human subjects, pointed out the direction for the future of tourism development. Coastal tourism resources of ecological original makes people at the same time in the practice of ecological tourism began the practice of the seashore ecotourism. Based on the study, however, at present China's coastal city of ecological tourism environment quality overall level is not high, and the gap between the cities, for optimization of 12 coastal city, the ecological environment and resources has some shortage, the rest of the coastal city. To develop ecological tourism must rely on the environment, has become an indisputable fact. Coastal ecological tourism at home and abroad is presented in this paper based on the analysis of the research of theory and practice, based on ecology, environmental ecology, ecological carrying capacity and sustainable development, Marine science, regional tourism development, economics, DEA (data envelopment analysis), and other disciplines theory study, the content of a scientific, research conclusion other analysis result has a certain similarity, therefore, the research result is credible, has a certain theoretical significance and practical value.

\section{Acknowledgements}

(1)Heilongjiang Provincial Department of Education Science and Technology Research Project (12542284) (2) Heilongjiang Province in 2014 college Innovation Project201410233024 （3） Mudanjiang Municipal Science and Technology Project140614 (4) Mudanjiang Teachers College research (LXYKY201406) (5)Mudanjiang Teachers College research (py2013026) (6)Mudanjiang Teachers College research ( ky201005) ( 7 ) Mudanjiang Teachers College educational reform(12-XJ14050) （8） Mudanjiang Teachers College educational reform(12-XJ14052) (9) Mudanjiang Teachers College educational reform(12-XJ14055).

\section{References}

[1] C. Manasakis, A. Apostolakis, and G. Datseris: International Journal of Contemporary Hospitality Management, Vol.25 (2013) No.4, p. 510.

[2] J. ZHANG, Q. ZONG, and Q. YUAN: Economic Geography, Vol.1 (2013), p. 27.

[3] C.D. Köksal, and A.A. Aksu: Tourism Management, Vol.28 (2007) No.3, p. 830.

[4] J.L. Hu, and H.S. Shieh, C.H. Huang: Asia Pacific Journal of Tourism Research, Vol.14 (2009) No.4, p. 371.

[5] C.P. Barros: Annals of Tourism Research, Vol.32 (2005) No.2, p. 456. 